\title{
Bioavailability of lignans in human subjects
}

\author{
Thomas Clavel ${ }^{1,2}$, Joël Doré ${ }^{2}$ and Michael Blaut ${ }^{1 *}$ \\ ${ }^{1}$ Department of Gastrointestinal Microbiology, Institute of Human Nutrition Potsdam-Rehbrücke, \\ Arthur-Scheunert-Allee 155, 14558 Nuthetal, Germany \\ ${ }^{2}$ Unit of Ecology and Physiology of the Digestive Tract, \\ National Institute for Research in Agriculture, Jouy-en-Josas, France
}

\begin{abstract}
Dietary lignans are phyto-oestrogens that possibly influence human health. The present review deals with lignan bioavailability, the study of which is crucial to determine to what extent metabolism, absorption and excretion of lignans alter their biological properties. Since intestinal bacteria play a major role in lignan conversion, for instance by producing the enterolignans enterodiol and enterolactone, emphasis is put on data obtained in recent bacteriological studies.
\end{abstract}

Phyto-oestrogens: Lignans: Enterolignans: Bioavailability: Human intestinal microbiota

\section{Introduction}

Phyto-oestrogens are dietary compounds of plant origin that mainly include flavonoids and lignans. Since their chemical structure is similar to those of oestrogens, they have been studied for their involvement in hormone-related disorders, such as reproductive failure and breast cancer (Setchell \& Adlercreutz, 1988). Meanwhile, it has become clear that it is crucial to study the bioavailability of phyto-oestrogens to evaluate the relevance of their health effects. The trend to consume increasing amounts of phyto-oestrogen-containing foods in Western countries shows the importance of studying the fate of phyto-oestrogens in the human body. Because abundant data are already available on flavonoids, the present review focuses on lignans.

A prerequisite for investigating lignan bioavailability is to accurately determine their occurrence in foods and to estimate their intake in human populations. Although flaxseed is the main source of lignans (approximately $4 \mathrm{mg} / \mathrm{g}$ dried mass), a variety of cereals, fruits, vegetables, legumes and beverages also contain lignans in substantial concentrations (10 ng to $400 \mu \mathrm{g} / \mathrm{g}$ ) (Milder et al. 2005a). Thus, lignans are found in a wide range of foods consumed daily in Western countries. Secoisolariciresinol diglucoside (SDG), its aglycone secoisolariciresinol (SECO), and matairesinol (MAT) are the most frequently studied dietary lignans. They have been studied for their possible role in the prevention of breast and prostate cancer $(\mathrm{McCann}$ et al. 2005; Thompson et al. 2005) and atherosclerosis (Prasad, 2005). They have also been used as model substrates to assess the bacterial production of the enterolignans enterodiol (ED) and enterolactone (EL) (Borriello et al. 1985), the biological properties of which are proposed to be more potent than those of plant lignans (Brooks \& Thompson, 2005; Jacobs et al. 2005). Numerous data presented in the present review deal primarily with SDG. However, it must be emphasised that enterolignans are produced from plant lignans other than SDG and MAT (Axelson et al. 1982), such as arctigenin, arctiin, 7-hydroxymatairesinol, isolariciresinol, lariciresinol (LARI), pinoresinol (PINO), sesamin and syringaresinol (Thompson et al. 1991; Liggins et al. 2000; Heinonen et al. 2001; Xie et al. 2003a, b; Penalvo et al. 2005). Enterolignans are also produced from lignins in rats (Begum et al. 2004). Recent studies agree on the need to expand databases on the lignan content of foods in order to more accurately determine dietary intakes of enterolignan precursors. Milder et al. (2005b) estimated that the total mean intake of LARI, MAT, PINO and SECO is approximately $1 \mathrm{mg} / \mathrm{d}$ in Dutch adults. Although the authors did not systematically take into account the influence of food processing on lignan concentrations and that lignan intake may vary between individuals and study populations, an appealing goal remains to know what proportion of this daily ingested $\mathrm{mg}$ of plant lignans may be metabolised in the digestive tract, be absorbed and eventually reach target tissues.

The aim of the present article is to provide a comprehensive and critical overview of the current knowledge on lignan bioavailability in human subjects, including data on the production, origin and physiological concentrations of lignan metabolites, with emphasis on the influence of intestinal bacteria on lignan bioavailability.

\footnotetext{
Abbreviations: ED, enterodiol; EN, enterolactone; LARI, lariciresinol; MAT, matairesinol; PINO, pinoresinol; SDG, secoisolariciresinol diglucoside; SECO, secoisolariciresinol.

*Corresponding author: Dr Michael Blaut, fax +49 03320088 407, email blaut@mail.dife.de
} 


\section{Lignan metabolism in the upper part of the gastrointestinal tract}

Host mechanisms, such as saliva action and chewing in the mouth, chemical hydrolysis in the stomach and mucosal enzymic activities, probably influence lignan bioavailability in the upper part of the gastrointestinal tract. However, the relevance of these processes is essentially unknown.

Results obtained in our laboratory showed that SDG was stable after $3 \mathrm{~h}$ at $37^{\circ} \mathrm{C}$ in artificial stomach juice (Clavel et al. 2006a). Similar results were reported for other glycosylated lignans in rat gastric juice (Nose et al. 1992). This agrees with data obtained by Mazur (2000), who found that glycosidic bonds of SDG are difficult to hydrolyse. For lignan extraction from foods, the authors used harsh conditions $(2 \mathrm{M}-\mathrm{HCl}$, $100^{\circ} \mathrm{C}, 2 \cdot 5 \mathrm{~h}$ ) to obtain SECO. SDG was also stable after $3 \mathrm{~h}$ at $37^{\circ} \mathrm{C}$ in artificial intestinal juice (Clavel et al. 2006a). Thus, it is possible that SDG is not hydrolysed during its passage through the stomach and small intestine.

While deglycosylation of flavonoids by host enzymes occurs in the mouth and small intestine (Walle et al. 2005), studies have not yet been conducted with lignans. Germ-free animal or in situ rat intestinal perfusion (Arts et al. 2004) models could be used to gain basic knowledge on the role of host mechanisms in lignan conversion, such as epithelial deglycosylation and absorption of plant lignans. Penalvo et al. (2004) recovered approximately $2 \%$ of the ingested dose of PINO and LARI in the plasma of four individuals $1 \mathrm{~h}$ after intake of $50 \mathrm{~g}$ sesame seeds. This suggests that a certain amount of ingested plant lignans may be quickly absorbed. This is in agreement with the detection of plant lignans in urine (Bannwart et al. 1989; Lampe et al. 1999; Hutchins et al. 2000; Nurmi et al. 2003). However, mechanisms responsible for uptake of plant lignans in the upper part of the gastrointestinal tract are unknown.

Due to rapid swallowing, it is unlikely that oral bacteria contribute to the conversion of plant lignans. The same applies to the oesophagus and stomach, where physical and chemical conditions do not favour bacterial colonisation. In contrast, at cell densities of approximately $10^{7}$ viable cells/g dried content in the ileum and $10^{12}$ cells/g in the colon, intestinal bacteria are considered to be a major factor that influences lignan bioavailability.

\section{Production of enterolignans by intestinal bacteria}

In vitro conversion of plant lignans by faecal slurries (Borriello et al. 1985; Thompson et al. 1991) and studies with germ-free rats (Axelson \& Setchell, 1981) have shown that intestinal bacteria are crucial for enterolignan production. To convert SDG to EL, bacteria catalyse four sequential reactions: $O$-deglycosylation, $O$-demethylation, dehydrogenation and dehydroxylation (Fig. 1) (Wang et al. 2000). Enterolignan production from LARI and PINO includes one and two additional reduction steps, respectively (Xie et al. 2003b).

\section{Diversity of lignan-converting bacteria and prevalence of enterolignan production}

The production of enterolignans from SDG requires the interaction of phylogenetically and functionally distantly related anaerobic bacteria (Fig. 1). The ability to $O$-deglycosylate SDG has been demonstrated for closely related species of the genera Bacteroides and Clostridium (Clavel et al. 2006b,c). The $O$-demethylation and dehydroxylation steps underlying SECO conversion are catalysed by several strains of Ruminococcus productus and Eggerthella lenta, respectively (Clavel et al. 2006b). Thus, the presence of different SDG-converting bacteria in the intestine may explain the high prevalence of enterolignan production in human subjects (Clavel et al. 2005). In our laboratory, enterolignans (ED + EL) were produced by all thirty-one human faecal samples tested. One sample from a male adult did not produce EL. Although these data were obtained with SECO only, bacteria involved in enterolignan production from SDG also convert other plant lignans. $R$. productus not only catalyses the $O$-demethylation of SECO, but also the $O$-demethylation of LARI, MAT, PINO and of a variety of other methylated aromatic compounds (Clavel et al. 2006a). E. lenta catalyses both the dehydroxylation of di-demethylated SECO and the reduction of PINO to LARI and of LARI to SECO. These data indicate that enterolignan production from various plant lignans results from a network of reactions (Fig. 1). It should be kept in mind that intestinal bacteria other than the ones identified so far may contribute to the conversion of plant lignans.

\section{Occurrence of lignan-converting bacteria in relation to host factors}

Most species mentioned in Fig. 1 are common members of dominant bacterial groups in the human intestine (Finegold et al. 1983; Suau et al. 1999). Culture-based enumerations of SECO-converting bacteria showed that organisms involved in the production of ED occurred at a mean cell density of $6 \times 10^{8}$ cells/g faeces (Clavel et al. 2005). In contrast, organisms involved in the production of EL from SECO were detected at a mean cell density of $3 \times 10^{5}$ cells/g. Since the occurrence of the latter organisms was related to the amount of EL produced, it is conceivable that variations in the cell density of lignan-converting bacteria explain the marked inter-individual differences observed for enterolignan production (Mazur et al. 2000; Clavel et al. 2005; Kuijsten et al. 2005b). However, this needs to be confirmed by future human intervention studies, in which proportions of lignan-converting bacteria could be compared with concentrations of ED and EL in biological matrices.

Interestingly, women tend to harbour more enterolignanproducing bacteria than men (Clavel et al. 2005). However, this was not associated with variations in proportions of dominant bacterial groups, possibly due to a limited number of samples. Nevertheless, this finding implies that host factors influence the bacterial production of enterolignans. In this context, it is worthwhile to discuss the role of the SECO-dehydroxylating species Clostridium scindens and $E$. lenta in the dehydroxylation of endogenous compounds that undergo enterohepatic circulation. E. lenta has been studied for its involvement in 21-dehydroxylation of biliary steroids (Feighner \& Hylemon, 1980), C. scindens for its ability to $7 \alpha$-dehydroxylate primary bile acids (Doerner et al. 1997) and to synthesise desmolase and 20 $\alpha$-hydroxysteroid 


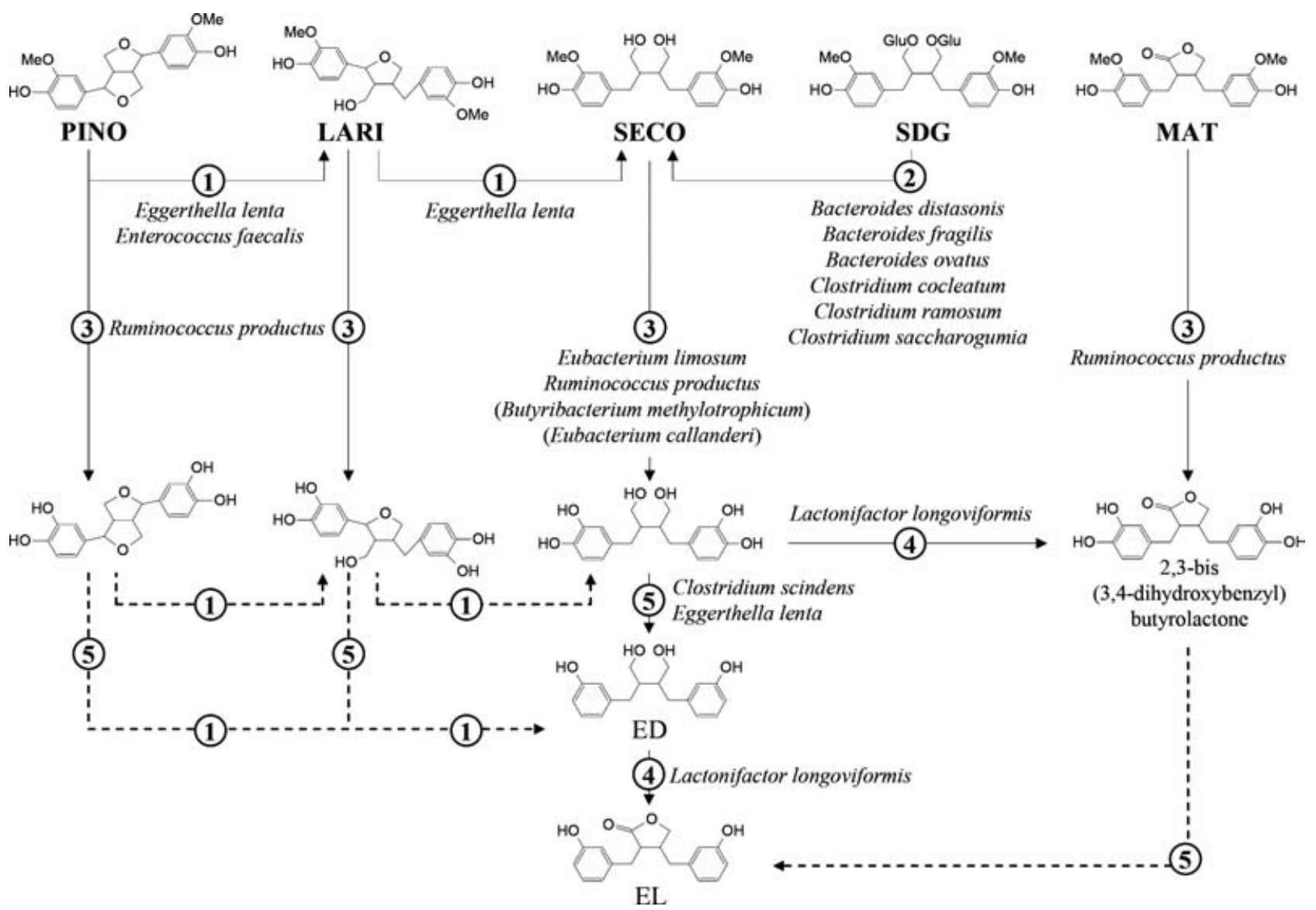

Fig. 1. Conversion of the plant lignans pinoresinol (PINO), lariciresinol (LARI), secoisolariciresinol (SECO), secoisolariciresinol diglucoside (SDG) and matairesinol (MAT) by human intestinal bacteria. Bacterial names are identified next to the reactions catalysed by the given organisms. Reactions are: (1) reduction; (2) O-deglycosylation; (3) O-demethylation; (4) dehydrogenation; (5) dehydroxylation. The SECO-demethylating species Butyribacterium methylotrophicum and Eubacterium callanderi are not yet known as members of the human intestinal microbiota. (---), Reactions for which no bacteria have been identified so far; ED, enterodiol; EL, enterolactone.

dehydrogenase (Krafft et al. 1987), both of which are involved in the metabolism of steroid hormones. It is conceivable that sex differences in intestinal levels of steroid hormones, for example, oestrogens, progesterone and testosterone, influence metabolic activities of bacteria capable of converting structurally related dietary compounds. This applies to the ability of $C$. scindens and E. lenta to dehydroxylate SECO. The role of progesterone might be of particular interest. Bacterial dehydroxylases are involved in progesterone metabolism (Feighner \& Hylemon, 1980). Also, progesterone relaxes smooth muscle tone resulting in a longer intestinal transit time (Bielefeldt et al. 1996). Shoda et al. (1995) and Kilkkinen et al. (2001) reported a positive correlation between intestinal transit and bacterial production of secondary bile acids and between serum EL concentration and constipation, respectively. Some bacteria, including $C$. scindens and strains of Eubacterium species, have several bile acid-inducible (bai) genes, which encode enzymes of the bile acid $7 \alpha$-dehydroxylation pathway (Doerner et al. 1997). Thus, progesterone levels and transit time may influence the conversion of dietary lignans by increasing their availability to bacteria or by inducing bacterial activities, directly or indirectly. However, to draw firm conclusions, it is imperative to characterise enzymes involved in lignan conversion. For example, enzyme expression could be assessed by proteomic analysis in response to the presence or absence of substrate. Another approach would be to screen metagenomic libraries of human intestinal microbiota for bacterial clones catalysing reactions underlying lignan conversion.

\section{Influence of bacterial dehydrogenation on metabolite production}

Of the five reactions underlying bacterial production of EL, the dehydrogenation step is of particular interest. First of all, lignan-dehydrogenating bacteria are subdominant members of intestinal microbiota (mean cell density of about $10^{5}$ cells/g). Only one strain capable of dehydrogenating lignans was identified, namely Lactonifactor longoviformis DSM $17459^{\mathrm{T}}$ (Clavel et al. 2006c). More work is needed to quantify this organism in faeces but, considering that EL production is detected in most individuals (Clavel et al. 2005; Kuijsten et al. 2005b), either the prevalence of $L$. longoviformis is high in human subjects or other not yet 
identified organisms catalyse the dehydrogenation step underlying EL production.

L. longoviformis seems to catalyse only the enantiospecific conversion of (+)-ED to (+)-EL (Clavel et al. $2006 c$ ). Xie et al. (2003a) reported the ability of faecal bacteria to produce $(+)$-EL and $(-)$-EL from different precursors and proposed that the absolute configuration of lignans is preserved throughout bacterial conversion. This agrees with data obtained in rats by Saarinen et al. (2002). We hypothesise that so-far unidentified bacteria dehydrogenate the (-)-enantiomer of lignans. Since the absolute configuration may influence production rates and biological properties of enterolignans, stereochemistry should be taken into consideration in future studies on bacterial production and biological properties of lignan metabolites. Concerning plant lignans, the (+)-enantiomer of SDG was detected at proportions of more than $90 \%$ total SDG in two flaxseed species (Sicilia et al. 2003). However, this ratio may vary in other flaxseed species and in dietary sources other than flaxseed. In a recent study (Knust et al. 2006), (-)-SDG was detected as the major enterolignan precursor in flaxseed, but the authors did not specify the flaxseed species tested. Xia et al. (2001) purified an enantio-specific enzyme from plants of Forsythia intermedia and Podophyllum peltatum that dehydrogenates (-)-SECO to (-)-MAT. Concerning LARI and MAT, one enantiomer of each was found in large excess in flaxseed (Sicilia et al. 2003), but stereochemistry was not determined. We conclude that the stereochemistry of plant lignans needs to be further investigated in order to accurately estimate physiological levels of active lignan metabolites.

The study of lignan conversion by L. longoviformis led to the identification of 2,3-bis(3,4-dihydroxybenzyl)butyrolactone, a new intermediate in the formation of EL from SDG. This shows that enterolignan production from a single precursor may occur through different pathways (Fig. 1). However, it is difficult to make assumptions on the predominance of any of these pathways in vivo, and how this influences conversion rates and biological effects of lignans. Adlercreutz et al. (1993a) found that the ability of 2,3-bis(3,4-dihydroxybenzyl)butyro-lactone (referred to as $4,4^{\prime}$-dihydroxy-EL in the study) to inhibit aromatase activity was higher than that of EL. Which lignan metabolites are formed by bacteria in vivo and how they differ between individuals remains a key issue. These metabolites may not necessarily be ED and EL. The presence of certain bacterial groups in faeces might be a good indicator for certain patterns of lignan metabolites and their rate of formation. In the future, in vitro continuous-culture systems could be used to grow mixed cultures of lignan-converting strains under controlled conditions in order to assess how changes in community composition influence the production of lignan metabolites.

\section{Limitations of bacteriological studies}

Even if bacteriological data are crucial for the study of lignan bioavailability, two major limitations must be pointed out. First, to characterise the mechanisms underlying bacterial conversion of lignans, it is necessary to work not only with pure compounds, but also even with pure enantiomers.
However, this makes it difficult to estimate rates of enterolignan production in vivo, since the fate of pure compounds does not necessarily reflect lignan availability from complex food matrices. For example, lignans are primarily found in the outermost layers of seeds and may not be easily accessible to bacteria (Mazur, 2000). Crushing and milling of flaxseed was shown to improve enterolignan bioavailability (Kuijsten et al. 2005a). Furthermore, esterlinked and 3-hydroxy-3-methyl-glutaric-acid-interconnected polymers of SDG have been described in flaxseed (Ford et al. 2001; Kamal-Eldin et al. 2001). Although mucosal and bacterial esterase activities towards phenolic acids have been reported in human subjects (Andreasen et al. 2001) and although enterolignans are produced from lignins in rats (Begum et al. 2004), it is unclear to what extent lignan polymers are hydrolysed in the human intestine. Hence, to assess lignan conversion rates, it would be preferable to use complex food matrices, as done previously by Thompson et al. (1991) and Aura et al. (2006) with faecal slurries. Second, defined mixed cultures catalyse the conversion of SDG to EL in vitro (Clavel et al. 2006b). However, it is difficult to draw any conclusion on the role that each of the identified lignanconverting species plays in vivo. Experiments with gnotobiotic animals could bring to the test the relevance of these in vitro findings. Besides, batch cultures of faecal slurries do not accurately mimic the physico-chemical conditions in the intestine. Depending on the media and incubating conditions used, growth of specific bacterial groups may be favoured. This would lead either to overgrowth of lignan-converting bacteria with ensuing overestimation of corresponding cell densities, or to overgrowth of nonconverting bacteria. This may also explain the $60 \%$ recovery of enterolignans after incubating SECO with faecal slurries for $48 \mathrm{~h}$ (Clavel et al. 2005). Heinonen et al. (2001) reported a comparable recovery ( $72 \%$ of the SECO was converted to enterolignans within $24 \mathrm{~h}$ ) and noted that the efficacy of conversion varied between plant lignans.

\section{Enterolignan absorption and blood levels}

\section{Enterolignan absorption}

Once produced by intestinal bacteria, enterolignans may be efficiently absorbed, conjugated and the resulting metabolites excreted by enterocytes, as proposed by in vitro experiments with human colonic cell cultures (Jansen et al. 2005). EL-sulfate, -glucuronide and ED-glucuronide were detected after exposing cells to enterolignans, but molar proportions were not determined. Conjugation and excretion occurred within $8 \mathrm{~h}$ and EL was metabolised or excreted more rapidly than ED. However, these results must be regarded with caution concerning the kinetics of metabolite production, since cancer cell lines might have an increased conjugation and efflux activity. Besides, only two of the three cell lines tested (HT29 and CaCo-2 cells) were responsive to enterolignan exposure.

\section{Baseline concentrations of lignans in blood}

In most studies on blood levels of lignans, total lignans are measured following hydrolysis of conjugates. However, 
conjugation certainly influences the biological properties of lignans, even if conjugation patterns in blood do not necessarily reflect those in target tissues. Based on the analysis of blood samples from twenty-seven women, Adlercreutz et al. (1993b) proposed that the biologically active fraction of enterolignans, including free, mono- and di-sulfated ED and EL, makes up 21-25\% of total (conjugated plus unconjugated) enterolignans. The major fraction (approximately $80 \%$ total enterolignans) included biologically inactive mono- and di-glucuronides and sulfoglucuronides. These ratios and blood concentrations of enterolignans probably depend on study cohorts. Nonetheless, it is proposed that average baseline concentrations of enterolignans (in the blood of subjects on their usual diet) are in the range of 10 to $25 \mathrm{nmol} / \mathrm{l}$ (Adlercreutz et al. 1998; Hong et al. 2002; Horner et al. 2002; Grace et al. 2003; Kilkkinen et al. 2003; Valentin-Blasini et al. 2003; Kuijsten et al. 2005a; Low et al. 2005). Recently, the plant lignans LARI and MAT were detected in human serum at concentrations sometimes higher than those of ED and EL (Smeds et al. 2006). For instance, the highest concentration of LARI was $190 \mathrm{nmol} / \mathrm{l}$ in the serum of one female subject. On the other hand, SECO was not detected in any of the ten samples tested. Clearly, marked inter-individual differences are observed. In particular, dietary habits influence blood concentrations of lignans. Intake of vegetables, fibres and wholegrain products has been associated with higher EL concentrations (Kilkkinen et al. 2001; Horner et al. 2002). The highest concentration of EL reported in the literature exceeded $1 \mu \mathrm{mol} / 1$ in the blood of one vegan postmenopausal woman (Adlercreutz et al. 1993b). Hence, it has been proposed that blood concentrations of EL are related to the intake of plant lignans (Kilkkinen et al. 2003).

\section{Blood levels of lignans after dietary intervention}

A growing number of human studies have shown that dietary intervention with lignan-containing foods leads to an increase in blood levels of enterolignans in nearly all individuals (Nesbitt et al. 1999; Juntunen et al. 2000; Mazur et al. 2000; Stumpf et al. 2000; Jacobs et al. 2002; Tarpila et al. 2002; Kuijsten et al. 2005a). Since most of these studies used amounts of whole grains, oilseeds or fruits that are relevant in terms of daily food consumption, moderate changes in dietary habits may significantly alter blood levels of enterolignans. For instance, Mazur et al. (2000) and Kuijsten et al. (2005a) showed that blood levels of EL significantly increased after a single meal of $500 \mathrm{~g}$ strawberries or after daily consumption of approximately $20 \mathrm{~g}$ flaxseed for $10 \mathrm{~d}$. Because the type and duration of intervention vary greatly between studies, it is hard to tell whether enterolignan levels in biological matrices reach maximum values beyond a certain ingested dose of dietary precursors or after intake over long periods. During a 12-week intervention favouring intake of lignan-containing foods (Stumpf et al. 2000), most increase in the blood concentration of EL occurred during the first 6 weeks (median values were $12 \cdot 2,17.2$ and $19.5 \mathrm{nmol} / \mathrm{l}$ at baseline and after 6 and 12 weeks, respectively; $n$ 85). Conversely, Tarpila et al. (2002) observed a continuous increase during 4 months of intervention with flaxseed (serum EL concentrations were 33,52 and $70 \mathrm{nmol} / \mathrm{l}$ at baseline and after 2 and 4 months, respectively; $n$ 80). However, the participants of the latter study also ingested inulin, which possibly altered microbial activities. Juntunen et al. (2000) proposed that a daily intake of more than $90 \mathrm{~g}$ rye bread (approximately $300 \mu \mathrm{g}$ lignans) (Milder et al. 2005a) for 4 weeks does not trigger a further increase in blood levels of enterolignans. On the other hand, Nesbitt et al. (1999) observed a dose-response in daily urinary excretion of lignans after intake of 5,15 or $25 \mathrm{~g}$ flaxseed/d for $7 \mathrm{~d}$ and did not report a plateau effect at $25 \mathrm{~g} / \mathrm{d}$ (approximately $75 \mathrm{mg}$ lignans) (Milder et al. 2005a). Thus, we hypothesise that a constant increase in the amount of enterolignans produced in the intestine occurs if dietary intervention is long enough, maybe due to adaptive responses in bacterial activities, which are not necessarily accompanied by changes in bacterial diversity or proportions. However, blood levels of enterolignans may not exceed an individual-specific threshold, due to adaptive responses in host metabolism and excretion mechanisms. The detection of LARI and MAT in blood implies that some plant lignans are rapidly absorbed as such and that the microbial capacities to produce enterolignans can be saturated beyond intake of a certain amount of precursors. However, it is to date not possible to estimate this amount. Future intervention studies in human subjects should assess changes in blood concentration of lignans in relation to changes in intestinal microbiota and should include measurements when dietary treatment is over to determine how durable changes are.

\section{Blood levels in relation to bacterial conversion of lignans}

Based on results obtained in our laboratory (Clavel et al. 2005) and on a recent pharmacokinetic study by Kuijsten et al. (2005b) who measured enterolignans in blood and urine after a single dose of $500 \mathrm{mg}$ SDG, we can draw a number of conclusions which are relevant to both bacteriological and human studies:

(1) Inter-individual differences in cell densities of enterolignan-producing bacteria may explain interindividual differences in blood concentrations of enterolignans.

(2) The detection of enterolignans in the blood of most individuals is most probably linked to the high prevalence of enterolignan-producing bacteria and implies that health effects associated with enterolignans are relevant to all individuals.

(3) The predominance of EL $v$. ED in blood may be partly due to the enterohepatic circulation of ED. Since the ED:EL ratio might be important with regard to health effects, it would be interesting to know whether individuals with low cell densities of lignan-dehydrogenating organisms are those in whom ED is the main metabolite detected after ingestion of SDG.

(4) Kuijsten et al. (2005b) found that enterolignans are first detectable in blood 8 to $10 \mathrm{~h}$ after dietary intake. Although pharmacokinetic parameters may vary between intake of a single dose of SDG in water and continuous intake of SDG-containing foods, this finding agrees with previous data (Nesbitt et al. 1999; 
Mazur et al. 2000) and confirms that enterolignans are primarily produced and absorbed in the colon.

(5) The tendency of women to have higher cell densities of enterolignan-producing bacteria than men (Clavel et al. 2005) agrees with higher blood concentrations of enterolignans in women (Jacobs et al. 2002; Kilkkinen et al. 2003; Kuijsten et al. 2005b). Another sex difference is the earlier appearance of enterolignans in the blood of women (Kuijsten et al. 2005b). However, the cohort size was small in three of the cited studies $(n \leq 20)$ (Jacobs et al. 2002; Clavel et al. 2005; Kuijsten et al. 2005b). Moreover, it is necessary to take into account sex differences in dietary intake and blood volume when comparing blood levels of enterolignans between women and men. In one study involving twenty-one women and eighteen men with slightly elevated serum cholesterol levels, Juntunen et al. (2000) refuted the assumption of significant sex differences in lignan metabolism after rye-bread intake. After a 4-week intervention, women had a non-significant higher mean concentration of EL in serum than men $(39.3$ v. $28.1 \mathrm{nmol} / \mathrm{l})$ and lignan intake on a per kg body-weight basis did not differ. When assessing sex differences, detailed information on the menstrual cycle should be given too. Early studies showed that enterolignan excretion is associated with pregnancy and the menstrual cycle, although the number of samples analysed was limited (Setchell et al. 1979; Stitch et al. 1980). The possible role of progesterone detailed above would partly explain higher excretion of enterolignans during the mid-luteal phase and early pregnancy. However, a study by Lampe et al. (1994) does not support association between enterolignan excretion and the menstrual cycle. Although more work is required to achieve a consensus in results on this topic, a relationship between lignan and hormone bioavailability is supported by the observed alteration of both the menstrual cycle and levels of sex hormones following flaxseed consumption (Phipps et al. 1993; Brooks et al. 2004).

Beyond the crucial role of bacteria in lignan conversion, the study by Kuijsten et al. (2005b) highlights the importance of host mechanisms in regulating lignan bioavailability. Hepatic metabolism, entero-hepatic circulation and excretion certainly regulate tissue exposure to the lignans produced in the intestinal tract.

\section{Hepatic metabolism of lignans and tissue concentrations}

Early work in rats suggested that lignans undergo enterohepatic circulation (Axelson \& Setchell, 1981). Since then, only two in vitro studies have investigated the production of lignan metabolites by the liver. Jacobs et al. (1999) obtained aliphatic and aromatic hydroxylated metabolites of ED and EL after incubating synthesised enterolignans with human hepatic microsomes. The authors also identified aromatic hydroxylated metabolites in the urine of two women and two men (Jacobs et al. 1999). Using hepatic microsomes too, Niemeyer et al. (2003) detected oxidative metabolites of MAT and SECO. The biological properties of these lignan metabolites remain to be determined and the hepatic conjugation of lignans in human subjects has to be proven.

In a study using a single dose of $\left[{ }^{3} \mathrm{H}\right] \mathrm{SDG}$ in twenty-four female Sprague-Dawley rats (Rickard \& Thompson, 1998), the twelve tissues analysed for the presence of radioactivity contained in total about $5 \%$ of the recovered dose of radioactivity. Most SDG metabolites were excreted within $48 \mathrm{~h}$ after administration. Approximately $30 \%$ of the recovered dose was detected in urine and $50 \%$ in faeces. The liver was one of the tissues with high concentrations of lignan metabolites. Other tissues with high concentrations were the intestine (mainly the caecum), kidney and uterus. In human subjects, lignan concentrations have been measured in semen, because in the early 1980s enterolignans were suspected to be of gonadal origin, in prostatic fluid and tissue and in breast cyst fluid because of their possible role in the prevention of prostate and breast cancer (McCann et al. 2005; Thompson et al. 2005). In semen of six men, EL occurred in both conjugated and unconjugated forms at concentrations between 63 and $557 \mathrm{nmol} / 1$ (Dehennin et al. 1982). In prostatic fluid, the mean concentration of EL ranged from $68 \mathrm{nmol} / 1$ in British men to $544 \mathrm{nmol} / 1$ in Portuguese men, in whom the highest concentrations exceeded $2 \mu \mathrm{mol} / \mathrm{l}$ (Morton et al. 1997). In prostatic tissue, enterolignan concentrations were two- to three-fold higher than in plasma (17-93 v. 7.5-29 nmol/l) (Hong et al. 2002), but the authors did not assess differences in tissue concentrations between ED and EL. In 191 women, the intracystic median concentration of EL was $63 \mathrm{nmol} / 1$ whereas the concentration in the serum was $17 \mathrm{nmol} / \mathrm{l}$ (Boccardo et al. 2003). These data indicate that tissue accumulation of lignans may occur. This is of primary importance with regard to the health effects of lignans. For instance, tissue accumulation of the plant lignan arctigenin could lead to changes in immune responses through modulation of MAP kinase kinase activity, NF- $\mathrm{B}$ activation and TNF $\alpha$ production (Cho et al. 1999). Tissue accumulation of lignan metabolites could also lead to the inhibition of steroid-metabolising enzymes (Adlercreutz et al. 1993a). If at all possible, future clinical studies focusing on the health effects of dietary lignans should include measurements of lignans in tissues. For example, lignan concentrations in breast tissues could be measured in studies with breast cancer patients scheduled for biopsy.

\section{Lignan excretion}

\section{Urinary excretion}

Urinary excretion has been the most widely studied aspect of lignan bioavailability. A few key points are summarised here. As in the case of blood levels, urinary excretion of enterolignans is characterised by higher baseline values of EL (100-5000 nmol/d) than of ED $(10-1000 \mathrm{nmol} / \mathrm{d})$ (Axelson \& Setchell, 1980; Adlercreutz et al. 1995b; Lampe et al. 1999; Hutchins et al. 2000). A dose-dependent increase in ED and EL excretion is observed after dietary supplementation of lignan-containing foods (Lampe et al. 1994; Hutchins et al. 2000) and enterolignan concentrations in urine correlate well with those in blood (Valentin-Blasini 
et al. 2003; Kuijsten et al. 2005b). However, while the mean proportion of free and sulfated enterolignans is approximately $20 \%$ in blood (Adlercreutz et al. 1993b), their proportion in urine is below $10 \%$ (Axelson \& Setchell, 1980; Adlercreutz et al. 1995b). Mono-glucuronidated and sulfoglucuronidated enterolignans ranged from 73 to $94 \%$ and from 1 to $17 \%$ of total urinary enterolignans, respectively. Similar percentages have been observed for the plant lignan MAT and for endogenous oestrogens (Axelson \& Setchell, 1980; Adlercreutz et al. 1995b). Interestingly, enterolignans were detected in the urine of a 6-year-old child at approximately $168 \mathrm{nmol} / \mathrm{d}$ (Axelson \& Setchell, 1980), which shows the potential of a child's intestinal microbiota to produce enterolignans. In the study by Kuijsten et al. . $(2005 b)$, the total amount of ED and EL detected in urine was $40 \%$ of the ingested dose of $500 \mathrm{mg} \mathrm{SDG}$, the majority of which was excreted within $2 \mathrm{~d}$. The residence time of enterolignans was lower in women than in men (17.3 v. 23.9 h). In earlier studies (Stitch et al. 1980; Setchell et al. 1981), both enantiomers of EL were detected in urine and the authors proposed that urinary EL is racaemic.

\section{Faecal excretion}

Very few data on faecal excretion of lignans are available. In nine omnivorous Finnish women consuming their usual diet, the daily amount of MAT and ED excreted in faeces was approximately 22 and $148 \mathrm{nmol}$, respectively (Adlercreutz et al. 1995a). The excretion of EL was much higher $(1-500 \mathrm{nmol} / \mathrm{d})$. The authors found that faecal excretion of lignans was 2- to 4-fold higher in nine vegetarian women but statistical analyses were not performed. In an intervention study with thirteen women consuming $10 \mathrm{~g}$ ground flaxseed/d in addition to their usual diet for a period of three menstrual cycles, Kurzer et al. (1995) observed baseline values of approximately 7, 80 and $640 \mathrm{nmol} / \mathrm{d}$ for MAT, ED and EL, respectively. After intervention, the excreted amounts of MAT, ED and EL significantly increased (12, 2-560 and $10300 \mathrm{nmol} / \mathrm{d}$, respectively). These data, and the fact that urinary excretion of MAT in thirty-one postmenopausal women did not increase after consumption of $10 \mathrm{~g}$ flaxseed/d for 7 weeks (Hutchins et al. 2000), suggest that MAT is efficiently converted to enterolignans in the intestine. Alternatively, MAT may be absorbed as such and subsequently metabolised, for example, hydroxylated, by host enzymes.

\section{Conclusion}

Table 1 summarises important facts on lignan bioavailability in human subjects. The study of lignan bioavailability requires the investigation of lignan absorption, metabolism and excretion at different body sites. The goal is to integrate all data to gain information on physiological concentrations of biologically active metabolites. To reach this goal, more work in needed. For instance, novel host and bacterial metabolites of lignans could be found and their biological properties investigated. Quantitative approaches must be used to determine production rates and ratios of lignan metabolites. Moreover, lignan bioavailability is characterised by marked inter-individuals differences. Future human studies should include intestinal microbiota analysis to help characterising inter-individual differences in the ability to metabolise dietary lignans. Finally, almost all studies on lignans highlight possible beneficial health effects and no adverse effects of lignans have been reported so far (Kulling

Table 1. Important data on lignan bioavailability in human subjects*

\begin{tabular}{|c|c|c|}
\hline & Findings & References \\
\hline Plant lignans & $\begin{array}{l}\text { Prevalence in foods: } 96 \% \ddagger \\
\text { Food content: } 0 \text { to } 3 \mathrm{~g} / \mathrm{kg} \text { fresh weight } \\
\text { Mean usual daily intake: about } 1 \mathrm{mg} \\
\text { Maximum usual daily intake: about } 78 \mathrm{mg} \\
\text { Detectable in blood and urine }\end{array}$ & $\begin{array}{l}\text { Milder et al. (2005a) } \\
\text { Milder et al. (2005b) } \\
\text { Bannwart et al. (1989); } \\
\quad \text { Smeds et al. (2006) }\end{array}$ \\
\hline \multicolumn{2}{|c|}{ Intestinal bacteria are crucial for the conversion of plant lignans in the human intestine } & $\begin{array}{l}\text { Axelson \& Setchell 1981); } \\
\text { Clavel et al. (2006b) }\end{array}$ \\
\hline Enterolignans & $\begin{array}{l}\text { Detectable in all individuals. EL is not detected in some } \\
\text { individuals on their usual diet } \\
\text { EL predominates in blood, urine and faeces of most } \\
\text { individuals (about 5- to } 10 \text {-fold higher amounts than ED) } \\
\text { Baseline concentrations in blood: } 10 \text { to } 25 \mathrm{nmol} / \mathrm{l} \\
\text { Free and sulfate fraction (about } 20 \% \text { ) } \\
\text { Baseline urinary excretion: } 300 \text { to } 3000 \mathrm{nmol} / \mathrm{d} \\
\text { Baseline faecal excretion: } 100 \text { to } 1500 \mathrm{nmol} / \mathrm{d} \\
\text { Dietary interventions increase blood concentration and } \\
\quad \text { excretion } \\
\text { Possible tissue accumulation }\end{array}$ & $\begin{array}{l}\text { Clavel et al. (2005); } \\
\text { Kuijsten et al. (2005b) } \\
\text { Adlercreutz et al. (1995a); } \\
\quad \text { Lampe et al. (1999); } \\
\text { Kuijsten et al. (2005b) } \\
\text { Adlercreutz et al. (1993b); } \\
\quad \text { Kilkkinen et al. (2001) } \\
\text { Lampe et al. (1999); } \\
\text { Hutchins et al. (2000); } \\
\quad \text { Nurmi et al. (2003) } \\
\text { Adlercreutz et al. (1995a) } \\
\text { Kurzer et al. (1995); } \\
\text { Mazur et al. (2000) } \\
\text { Morton et al. (1997) }\end{array}$ \\
\hline
\end{tabular}

EL, enterolactone; ED, enterodiol.

* The Table is meant to give a one-look overview of so-far acknowledged trends. The data list is not exhaustive. Values are given as references and vary between individuals and populations.

† Restricted to lariciresinol, matairesinol, pinoresinol and secoisolariciresinol.

$\ddagger$ Proportion of food items ( $n$ 109) containing detectable amounts of plant lignans. 
et al. 1998). However, it must be kept in mind that lignans can interact with highly sensitive hormonal systems. Lignan-containing nutritional supplements should be used with great caution, especially in infants and children or during pregnancy and lactation (Ward et al. 2000). No matter what health effects lignans have, it is essential to study their bioavailability.

\section{References}

Adlercreutz H, Bannwart C, Wahala K, Makela T, Brunow G, Hase T, Arosemena PJ, Kellis JT Jr \& Vickery LE (1993a) Inhibition of human aromatase by mammalian lignans and isoflavonoid phytoestrogens. Journal of Steroid Biochemistry and Molecular Biology 44, 147-153.

Adlercreutz H, Fotsis T, Kurzer MS, Wahala K, Makela T \& Hase T (1995a) Isotope dilution gas chromatographic-mass spectrometric method for the determination of unconjugated lignans and isoflavonoids in human feces, with preliminary results in omnivorous and vegetarian women. Analytical Biochemistry 225, $101-108$.

Adlercreutz H, Fotsis T, Lampe J, Wahala K, Makela T, Brunow G \& Hase T (1993b) Quantitative determination of lignans and isoflavonoids in plasma of omnivorous and vegetarian women by isotope dilution gas chromatography-mass spectrometry. Scandinavian Journal of Clinical and Laboratory Investigation $\mathbf{2 1 5}$, $5-18$.

Adlercreutz H, van der Wildt J, Kinzel J, Attalla H, Wahala K, Makela T, Hase T \& Fotsis T (1995b) Lignan and isoflavonoid conjugates in human urine. Journal of Steroid Biochemistry and Molecular Biology 52, 97-103.

Adlercreutz H, Wang GJ, Lapcik O, Hampl R, Wahala K, Makela T, Lusa K, Talme M \& Mikola H (1998) Time-resolved fluoroimmunoassay for plasma enterolactone. Analytical Biochemistry 265, 208-215.

Andreasen MF, Kroon PA, Williamson G \& Garcia-Conesa MT (2001) Intestinal release and uptake of phenolic antioxidant diferulic acids. Free Radical Biology and Medicine 31, 304-314.

Arts IC, Sesink AL, Faassen-Peters M \& Hollman PC (2004) The type of sugar moiety is a major determinant of the small intestinal uptake and subsequent biliary excretion of dietary quercetin glycosides. British Journal of Nutrition 91, 841-847.

Aura AM, Oikarinen S, Mutanen M, Heinonen SM, Adlercreutz HC, Virtanen H \& Poutanen KS (2006) Suitability of a batch in vitro fermentation model using human faecal microbiota for prediction of conversion of flaxseed lignans to enterolactone with reference to an in vivo rat model. European Journal of Nutrition 45, 45-51.

Axelson M \& Setchell KD (1980) Conjugation of lignans in human urine. FEBS Letters 122, 49-53.

Axelson M \& Setchell KD (1981) The excretion of lignans in rats evidence for an intestinal bacterial source for this new group of compounds. FEBS Letters 123, 337-342.

Axelson M, Sjovall J, Gustafsson BE \& Setchell KD (1982) Origin of lignans in mammals and identification of a precursor from plants. Nature 298, 659-660.

Bannwart C, Adlercreutz H, Wahala K, Brunow G \& Hase T (1989) Detection and identification of the plant lignans lariciresinol, isolariciresinol and secoisolariciresinol in human urine. Clinica Chimica Acta 180, 293-301.

Begum AN, Nicolle C, Mila I, Lapierre C, Nagano K, Fukushima K, Heinonen SM, Adlercreutz H, Remesy C \& Scalbert A (2004) Dietary lignins are precursors of mammalian lignans in rats. Journal of Nutrition 134, 120-127.
Bielefeldt K, Waite L, Abboud FM \& Conklin JL (1996) Nongenomic effects of progesterone on human intestinal smooth muscle cells. American Journal of Physiology 271, G370-G376.

Boccardo F, Lunardi GL, Petti AR \& Rubagotti A (2003) Enterolactone in breast cyst fluid: correlation with EGF and breast cancer risk. Breast Cancer Research and Treatment 79, $17-23$.

Borriello SP, Setchell KD, Axelson M \& Lawson AM (1985) Production and metabolism of lignans by the human faecal flora. Journal of Applied Bacteriology 58, 37-43.

Brooks JD \& Thompson LU (2005) Mammalian lignans and genistein decrease the activities of aromatase and 17betahydroxysteroid dehydrogenase in MCF-7 cells. Journal of Steroid Biochemistry and Molecular Biology 94, 461-467.

Brooks JD, Ward WE, Lewis JE, Hilditch J, Nickell L, Wong E \& Thompson LU (2004) Supplementation with flaxseed alters estrogen metabolism in postmenopausal women to a greater extent than does supplementation with an equal amount of soy. American Journal of Clinical Nutrition 79, 318-325.

Cho JY, Kim AR, Yoo ES, Baik KU \& Park MH (1999) Immunomodulatory effect of arctigenin, a lignan compound, on tumour necrosis factor-alpha and nitric oxide production, and lymphocyte proliferation. Journal of Pharmacy and Pharmacology 51, 1267-1273.

Clavel T, Borrmann D, Braune A, Doré J \& Blaut M (2006a) Occurrence and activity of human intestinal bacteria involved in the conversion of dietary lignans. Anaerobe 12, 140-147.

Clavel T, Henderson G, Alpert C-A, Philippe C, Rigottier-Gois L, Dore J \& Blaut M (2005) Intestinal bacterial communities that produce active estrogen-like compounds enterodiol and enterolactone in humans. Applied and Environmental Microbiology 71, 6077-6085.

Clavel T, Henderson G, Engst W, Doré J \& Blaut M (2006b) Phylogeny of human intestinal bacteria that activate the dietary lignan secoisolariciresinol diglucoside. FEMS Microbiology Ecology 55, 471-478.

Clavel T, Lippmann R, Gavini F, Doré J \& Blaut M (2006c) Clostridium saccharogumia sp. nov. and Lactonifactor longoviformis gen. nov., sp. nov., two novel human faecal bacteria involved in the conversion of the dietary phytoestrogen secoisolariciresinol diglucoside. Systematic and Applied Microbiology (In the Press). http://dx.doi.org/10.1016/j.syapm. 2006.02.003

Dehennin L, Reiffsteck A, Jondet M \& Thibier M (1982) Identification and quantitative estimation of a lignan in human and bovine semen. Journal of Reproduction and Fertility 66, 305-309.

Doerner KC, Takamine F, LaVoie CP, Mallonee DH \& Hylemon PB (1997) Assessment of fecal bacteria with bile acid 7 $\alpha$-dehydroxylating activity for the presence of bai-like genes. Applied and Environmental Microbiology 63, 1185-1188.

Feighner SD \& Hylemon PB (1980) Characterization of a corticosteroid 21-dehydroxylase from the intestinal anaerobic bacterium. Eubacterium lentum. Journal of Lipid Research 21, 585-593.

Finegold SM, Sutter VL \& Mathisen GE (1983) Normal indigenous intestinal flora. In Human Intestinal Microflora in Health and Disease, pp. 3-31 [DJ Henteges, editor]. New York: Academic Press.

Ford JD, Huang KS, Wang HB, Davin LB \& Lewis NG (2001) Biosynthetic pathway to the cancer chemopreventive secoisolariciresinol diglucoside-hydroxymethyl glutaryl ester-linked lignan oligomers in flax (Linum usitatissimum) seed. Journal of Natural Products 64, 1388-1397.

Grace PB, Taylor JI, Botting NP, Fryatt T, Oldfield MF, Al-Maharik N \& Bingham SA (2003) Quantification of 
isoflavones and lignans in serum using isotope dilution liquid chromatography/tandem mass spectrometry. Rapid Communications in Mass Spectrometry 17, 1350-1357.

Heinonen S, Nurmi T, Liukkonen K, Poutanen K, Wahala K, Deyama T, Nishibe S \& Adlercreutz H (2001) In vitro metabolism of plant lignans: new precursors of mammalian lignans enterolactone and enterodiol. Journal of Agriculture and Food Chemistry 49, 3178-3186.

Hong SJ, Kim SI, Kwon SM, Lee JR \& Chung BC (2002) Comparative study of concentration of isoflavones and lignans in plasma and prostatic tissues of normal control and benign prostatic hyperplasia. Yonsei Medical Journal 43, 236-241.

Horner NK, Kristal AR, Prunty J, Skor HE, Potter JD \& Lampe JW (2002) Dietary determinants of plasma enterolactone. Cancer Epidemiology Biomarkers and Prevention 11, 121-126.

Hutchins AM, Martini MC, Olson BA, Thomas W \& Slavin JL (2000) Flaxseed influences urinary lignan excretion in a dosedependent manner in postmenopausal women. Cancer Epidemiology Biomarkers and Prevention 9, 1113-1118.

Jacobs DR Jr, Pereira MA, Stumpf K, Pins JJ \& Adlercreutz H (2002) Whole grain food intake elevates serum enterolactone. British Journal of Nutrition 88, 111-116.

Jacobs E, Kulling SE \& Metzler M (1999) Novel metabolites of the mammalian lignans enterolactone and enterodiol in human urine. Journal of Steroid Biochemistry and Molecular Biology 68, 211-218.

Jacobs MN, Nolan GT \& Hood SR (2005) Lignans, bacteriocides and organochlorine compounds activate the human pregnane $\mathrm{X}$ receptor (PXR). Toxicology and Applied Pharmacology 209, $123-133$.

Jansen GH, Arts IC, Nielen MW, Muller M, Hollman PC \& Keijer J (2005) Uptake and metabolism of enterolactone and enterodiol by human colon epithelial cells. Archives of Biochemistry and Biophysics 435, 74-82.

Juntunen KS, Mazur WM, Liukkonen KH, Uehara M, Poutanen KS, Adlercreutz HC \& Mykkanen HM (2000) Consumption of wholemeal rye bread increases serum concentrations and urinary excretion of enterolactone compared with consumption of white wheat bread in healthy Finnish men and women. British Journal of Nutrition 84, 839-846.

Kamal-Eldin A, Peerlkamp N, Johnsson P, Andersson R, Andersson RE, Lundgren LN \& Aman P (2001) An oligomer from flaxseed composed of secoisolariciresinoldiglucoside and 3-hydroxy-3-methyl glutaric acid residues. Phytochemistry 58, 587-590.

Kilkkinen A, Stumpf K, Pietinen P, Valsta LM, Tapanainen H \& Adlercreutz H (2001) Determinants of serum enterolactone concentration. American Journal of Clinical Nutrition 73, 1094-1100.

Kilkkinen A, Valsta LM, Virtamo J, Stumpf K, Adlercreutz H \& Pietinen P (2003) Intake of lignans is associated with serum enterolactone concentration in Finnish men and women. Journal of Nutrition 133, 1830-1833.

Knust U, Hull WE, Spiegelhalder B, Bartsch H, Strowitzki T \& Owen RW (2006) Analysis of enterolignan glucuronides in serum and urine by HPLC-ESI-MS. Food and Chemical Toxicology 44, 1038-1049.

Krafft AE, Winter J, Bokkenheuser VD \& Hylemon PB (1987) Cofactor requirements of steroid-17-20-desmolase and 20 alpha-hydroxysteroid dehydrogenase activities in cell extracts of Clostridium scindens. Journal of Steroid Biochemistry and Molecular Biology 28, 49-54.

Kuijsten A, Arts IC, Van't Veer P \& Hollman PC (2005a) The relative bioavailability of enterolignans in humans is enhanced by milling and crushing of flaxseed. Journal of Nutrition 135, $2812-2816$
Kuijsten A, Arts IC, Vree TB \& Hollman PC (2005b) Pharmacokinetics of enterolignans in healthy men and women consuming a single dose of secoisolariciresinol diglucoside. Journal of Nutrition 135, 795-801.

Kulling SE, Jacobs E, Pfeiffer E \& Metzler M (1998) Studies on the genotoxicity of the mammalian lignans enterolactone and enterodiol and their metabolic precursors at various endpoints in vitro. Mutation Research 416, 115-124.

Kurzer MS, Lampe JW, Martini MC \& Adlercreutz H (1995) Fecal lignan and isoflavonoid excretion in premenopausal women consuming flaxseed powder. Cancer Epidemiology Biomarkers and Prevention 4, 353-358.

Lampe JW, Gustafson DR, Hutchins AM, Martini MC, Li S, Wahala K, Grandits GA, Potter JD \& Slavin JL (1999) Urinary isoflavonoid and lignan excretion on a Western diet: relation to soy, vegetable, and fruit intake. Cancer Epidemiology Biomarkers and Prevention 8, 699-707.

Lampe JW, Martini MC, Kurzer MS, Adlercreutz H \& Slavin JL (1994) Urinary lignan and isoflavonoid excretion in premenopausal women consuming flaxseed powder. American Journal of Clinical Nutrition 60, 122-128.

Liggins J, Grimwood R \& Bingham SA (2000) Extraction and quantification of lignan phytoestrogens in food and human samples. Analytical Biochemistry 287, 102-109.

Low YL, Taylor JI, Grace PB, et al. (2005) Polymorphisms in the CYP19 gene may affect the positive correlations between serum and urine phytoestrogen metabolites and plasma androgen concentrations in men. Journal of Nutrition 135, 2680-2686.

McCann MJ, Gill CI, McGlynn H \& Rowland IR (2005) Role of mammalian lignans in the prevention and treatment of prostate cancer. Nutrition and Cancer 52, 1-14.

Mazur WM (2000) Phytoestrogens: occurrence in foods, and metabolism of lignans in man and pigs. PhD Thesis, University of Helsinki.

Mazur WM, Uehara M, Wahala K \& Adlercreutz H (2000) Phytooestrogen content of berries, and plasma concentrations and urinary excretion of enterolactone after a single strawberry-meal in human subjects. British Journal of Nutrition 83, 381-387.

Milder IE, Arts IC, van de Putte B, Venema DP \& Hollman PC (2005a) Lignan contents of Dutch plant foods: a database including lariciresinol, pinoresinol, secoisolariciresinol and matairesinol. British Journal of Nutrition 93, 393-402.

Milder IE, Feskens EJ, Arts IC, Bueno de Mesquita HB, Hollman PC \& Kromhout D (2005b) Intake of the plant lignans secoisolariciresinol, matairesinol, lariciresinol, and pinoresinol in Dutch men and women. Journal of Nutrition 135, 1202-1207.

Morton MS, Chan PS, Cheng C, Blacklock N, Matos-Ferreira A, Abranches-Monteiro L, Correia R, Lloyd S \& Griffiths K (1997) Lignans and isoflavonoids in plasma and prostatic fluid in men: samples from Portugal, Hong Kong, and the United Kingdom. Prostate 32, 122-128.

Nesbitt PD, Lam Y \& Thompson LU (1999) Human metabolism of mammalian lignan precursors in raw and processed flaxseed. American Journal of Clinical Nutrition 69, 549-555.

Niemeyer HB, Honig DM, Kulling SE \& Metzler M (2003) Studies on the metabolism of the plant lignans secoisolariciresinol and matairesinol. Journal of Agriculture and Food Chemistry 51, 6317-6325.

Nose M, Fujimoto T, Takeda T, Nishibe S \& Ogihara Y (1992) Structural transformation of lignan compounds in rat gastrointestinal tract. Planta Medica 58, 520-523.

Nurmi T, Voutilainen S, Nyyssonen K, Adlercreutz H \& Salonen JT (2003) Liquid chromatography method for plant and mammalian lignans in human urine. Journal of Chromatography 798B, 101-110. 
Penalvo JL, Heinonen SM, Aura AM \& Adlercreutz H (2005) Dietary sesamin is converted to enterolactone in humans. Journal of Nutrition 135, 1056-1062.

Penalvo JL, Nurmi T, Haajanen K, Al-Maharik N, Botting N \& Adlercreutz H (2004) Determination of lignans in human plasma by liquid chromatography with coulometric electrode array detection. Analytical Biochemistry 332, 384-393.

Phipps WR, Martini MC, Lampe JW, Slavin JL \& Kurzer MS (1993) Effect of flax seed ingestion on the menstrual cycle. Journal of Clinical Endocrinology and Metabolism 77, $1215-1219$.

Prasad K (2005) Hypocholesterolemic and antiatherosclerotic effect of flax lignan complex isolated from flaxseed. Atherosclerosis 179, 269-275.

Rickard SE \& Thompson LU (1998) Chronic exposure to secoisolariciresinol diglycoside alters lignan disposition in rats. Journal of Nutrition 128, 615-623.

Saarinen NM, Smeds A, Makela SI, Ammala J, Hakala K, Pihlava JM, Ryhanen EL, Sjoholm R \& Santti R (2002) Structural determinants of plant lignans for the formation of enterolactone in vivo. Journal of Chromatography 777B, 311-319.

Setchell KD \& Adlercreutz H (1988) Mammalian lignans and phyto-oestrogens - recent studies on their formation, metabolism and biological role in health and disease. In Role of the Gut Flora in Toxicity and Cancer, pp. 315-345 [IR Rowland, editor]. London: Academic Press.

Setchell KD, Lawson AM, Axelson M \& Adlercreutz H (1979) The excretion of two new phenolic compounds during the human menstrual cycle and in pregnancy. In Research on Steroids, vol. IX, pp. 207-215 [H Adlercreutz, RD Bulbrook, HJ Van der Molen, A Vermeulen and F Sciarra, editors]. Amsterdam, Oxford and Princeton: Excerpta Medica.

Setchell KD, Lawson AM, Conway E, Taylor NF, Kirk DN, Cooley G, Farrant RD, Wynn S \& Axelson M (1981) The definitive identification of the lignans trans-2,3-bis(3-hydroxybenzyl)- $\gamma$ butyrolactone and 2,3-bis(3-hydroxybenzyl)butane-1,4-diol in human and animal urine. Biochemical Journal 197, 447-458.

Shoda J, He BF, Tanaka N, Matsuzaki Y, Osuga T, Yamamori S, Miyazaki H \& Sjovall J (1995) Increase of deoxycholate in supersaturated bile of patients with cholesterol gallstone disease and its correlation with de novo syntheses of cholesterol and bile acids in liver, gallbladder emptying, and small intestinal transit. Hepatology 21, 1291-1302.

Sicilia T, Niemeyer HB, Honig DM \& Metzler M (2003) Identification and stereochemical characterization of lignans in flaxseed and pumpkin seeds. Journal of Agriculture and Food Chemistry 51, 1181-1188.

Smeds AI, Hakala K, Hurmerinta TT, Kortela L, Saarinen NM \& Makela SI (2006) Determination of plant and enterolignans in human serum by high-performance liquid chromatography with tandem mass spectrometric detection. Journal of Pharmaceutical and Biomedical Analysis 41, 898-905.
Stitch SR, Toumba JK, Groen MB, Funke CW, Leemhuis J, Vink J \& Woods GF (1980) Excretion, isolation and structure of a new phenolic constituent of female urine. Nature 287, 738-740.

Stumpf K, Pietinen P, Puska P \& Adlercreutz H (2000) Changes in serum enterolactone, genistein, and daidzein in a dietary intervention study in Finland. Cancer Epidemiology Biomarkers and Prevention 9, 1369-1372.

Suau A, Bonnet R, Sutren M, Godon JJ, Gibson GR, Collins MD \& Dore J (1999) Direct analysis of genes encoding 16S rRNA from complex communities reveals many novel molecular species within the human gut. Applied and Environmental Microbiology 65, 4799-4807.

Tarpila S, Aro A, Salminen I, Tarpila A, Kleemola P, Akkila J \& Adlercreutz H (2002) The effect of flaxseed supplementation in processed foods on serum fatty acids and enterolactone. European Journal of Clinical Nutrition 56, 157-165.

Thompson LU, Chen JM, Li T, Strasser-Weippl K \& Goss PE (2005) Dietary flaxseed alters tumor biological markers in postmenopausal breast cancer. Clinical Cancer Research 11, $3828-3835$.

Thompson LU, Robb P, Serraino M \& Cheung F (1991) Mammalian lignan production from various foods. Nutrition and Cancer 16, 43-52.

Valentin-Blasini L, Blount BC, Caudill SP \& Needham LL (2003) Urinary and serum concentrations of seven phytoestrogens in a human reference population subset. Journal of Exposure Analysis and Environmental Epidemiology 13, 276-282.

Walle T, Browning AM, Steed LL, Reed SG \& Walle UK (2005) Flavonoid glucosides are hydrolyzed and thus activated in the oral cavity in humans. Journal of Nutrition 135, 48-52.

Wang LQ, Meselhy MR, Li Y, Qin GW \& Hattori M (2000) Human intestinal bacteria capable of transforming secoisolariciresinol diglucoside to mammalian lignans, enterodiol and enterolactone. Chemical and Pharmaceutical Bulletin 48, 1606-1610.

Ward WE, Jiang FO \& Thompson LU (2000) Exposure to flaxseed or purified lignan during lactation influences rat mammary gland structures. Nutrition and Cancer 37, 187-192.

Xia ZQ, Costa MA, Pelissier HC, Davin LB \& Lewis NG (2001) Secoisolariciresinol dehydrogenase purification, cloning, and functional expression. Implications for human health protection. Journal of Biological Chemistry 276, 12614-12623.

Xie LH, Ahn EM, Akao T, Abdel-Hafez AA, Nakamura N \& Hattori M (2003a) Transformation of arctiin to estrogenic and antiestrogenic substances by human intestinal bacteria. Chemical and Pharmaceutical Bulletin 51, 378-384.

Xie LH, Akao T, Hamasaki K, Deyama T \& Hattori M (2003b) Biotransformation of pinoresinol diglucoside to mammalian lignans by human intestinal microflora, and isolation of Enterococcus faecalis strain PDG-1 responsible for the transformation of (+)-pinoresinol to (+)-lariciresinol. Chemical and Pharmaceutical Bulletin 51, 508-515. 